\title{
Multiwalled Carbon Nanotube Synthesis Using Arc Discharge with Hydrocarbon as Feedstock
}

\author{
K. T. Chaudhary, ${ }^{1}$ Z. H. Rizvi, ${ }^{1}$ K. A. Bhatti, ${ }^{2}$ J. Ali, ${ }^{1}$ and P. P. Yupapin ${ }^{3}$ \\ ${ }^{1}$ Institute of Advanced Photonics Science (APSI), Nanotechnology Research Alliance, Universiti Teknologi Malaysia, \\ 81310 Johor Bahru, Malaysia \\ ${ }^{2}$ Physics Department, University of Engineering and Technology, Lahore 54000, Pakistan \\ ${ }^{3}$ Nanoscale Science and Research Alliance (N'SERA), Faculty of Science, King Mongkut's Institute of Technology Ladkrabang, \\ Bangkok 10520, Thailand \\ Correspondence should be addressed to K. T. Chaudhary; kashif.ali02@gmail.com
}

Received 1 July 2013; Revised 23 October 2013; Accepted 16 November 2013

Academic Editor: Xuedong Bai

Copyright (C) 2013 K. T. Chaudhary et al. This is an open access article distributed under the Creative Commons Attribution License, which permits unrestricted use, distribution, and reproduction in any medium, provided the original work is properly cited.

\begin{abstract}
Synthesis of multiwalled carbon nanotube (MWCNT) by arc discharge process is investigated with methane $\left(\mathrm{CH}_{4}\right)$ as background and feedstock gas. The arc discharge is carried out between two graphite electrodes for ambient pressures 100, 300, and 500 torr and arc currents 50, 70, and $90 \mathrm{~A}$. Plasma kinetics such as the density and temperature for arc discharge carbon plasma is determined to find out the contribution of physical parameters as arc current and ambient pressure on the plasma dynamics and growth of MWCNT. With increase in applied arc current and ambient pressure, an increase in plasma temperature and density is observed. The synthesized samples of MWCNT at different experimental conditions are characterized by transmission electron microscopy, scanning electron microscopy, Raman spectroscopy, Fourier transform infrared spectroscopy, and X-ray diffraction. A decrease in the diameter and improvement in structure quality and growth of MWCNT are observed with increase in $\mathrm{CH}_{4}$ ambient pressure and arc current. For $\mathrm{CH}_{4}$ ambient pressure 500 torr and arc current $90 \mathrm{~A}$, the well-aligned and straight MWCNT along with graphene stakes are detected.
\end{abstract}

\section{Introduction}

The unique structure of carbon nanotube (CNT) exhibits extraordinary electronic, thermal, and mechanical properties [1] which make them potential candidate for different technological applications [2-4]. Extensive efforts have been done to synthesize structured-controlled CNT. Several methods have been developed to synthesize CNT such as arc discharge [5], chemical vapor deposition (CVD) [6], and laser ablation [7]. Among these methods, arc discharge method is the promising technique capable to fabricate high quality CNT [8-10]. However, the control growth of CNT has not been accomplished due to lack of control and limited understanding of arc discharge plasma. A high influx of plasma species and high temperatures play key role in the growth of nanostructures. In order to realize and optimize the application of CNT, it is desired to understand the growth mechanism and influence of physical parameters (as ambient pressure, electrode geometry, applied current and voltage, gas flow, inter electrode distance, dynamics of plasma species, etc. [11]) on the growth of nanostructures. The arc current, ambient gas, and ambient pressure are the important parameter for arc discharge synthesis of MWCNT. The arc current supplies energy to anode causing the evaporation of anode surface and formation of arc plasma. The MWCNT with diameters largely distributed in the range of $40-60 \mathrm{~nm}$ are observed for arc discharge in absence of ambient gas. During arc discharge evaporation, the ambient gas acts as buffer gas and influence the growth and diameter distribution of MWCNT $[12,13]$. The arc discharge process for the synthesis of MWCNT is studied in different environments to control and improve their growth. For instance, in helium and argon environment the diameter distribution goes higher by varying the gas mixture from argon to helium and an average decrease in 
diameter is observed with increase in the argon-helium ratio [14]. In liquid nitrogen environment, for low arc current the spherical nanostructures with small diameter while for large arc current the CNT with large diameter are observed [15]. No cathode deposit is observed during discharge in deionized water; a layer of soot appeared at the surface of water which contains elongated rounded carbon structures such as nanoonions with some polyhedron structures and MWCNT [16]. In ammonia environment, no significant difference in the shapes and the structures of CNT is observed [17]. The hydrocarbon gases are widely used to grow the CNT using CVD and plasma enhanced chemical vapor deposition (PCVD) techniques [18-20]. However, there are not many investigations carried out on the hydrocarbon gases used as background and feedstock gas in arc discharge process.

In this investigative work, the MWCNT are synthesized by arc discharge process with $\mathrm{CH}_{4}$ as background and feedstock gas for different ambient pressures and applied arc currents. The plasma temperature and density are determined for different input powers and ambient pressures. The synthesized MWCNT for different experimental conditions are analyzed by microscopic and spectroscopic techniques to explore the influence of arc current and ambient pressure on the growth and structure quality of MWCNT. The well-aligned, straight, and small diameter MWCNT along graphene are obtained by arc discharge process in $\mathrm{CH}_{4}$ ambient environment.

\section{Experimental}

The arc discharge is carried out between two $99.99 \%$ pure graphite electrodes in presence of $\mathrm{CH}_{4}$ as background gas. The graphite rod with diameter $11 \mathrm{~mm}$ is used as cathode whereas the graphite rod with diameter $9 \mathrm{~mm}$ is used as anode. The optical spectrometer (Ocean Optics HR4000, $200-650 \mathrm{~nm}, 0.1 \mathrm{~nm}$ ) is used to record the optical emission spectrum of the discharge plasma in optical range $300-650 \mathrm{~nm}$. The radiations from the discharge plasma are focused by biconvex lens $(f=15 \mathrm{~cm}$ ) into the optical fiber of diameter $600 \mu \mathrm{m}$, which is connected to the optical spectrometer. The optical emission spectra are captured for applied arc current 50,70, and $90 \mathrm{~A}$ at pressure 100, 300, and 500 torr. Each spectrum is recorded for $300 \mathrm{~ms}$ integration time. Several spectra are recorded for each experimental condition and suitable spectra are selected to calculate the plasma temperature and density. The MWCNT samples synthesized at different experimental conditions are collected form cathode deposit and characterized by transmission electron microscopy (TEM), scanning electron microscopy (SEM), $\mathrm{X}$-ray diffraction (XRD) analysis, Raman spectroscopy and Fourier transform infrared (FTIR) spectroscopy.

\section{Results and Discussion}

The plasma temperatures and densities are estimated by in situ optical emission spectroscopy. The optical spectra are recorded for applied experimental conditions such as arc currents 50, 70, and $90 \mathrm{~A}$ and ambient pressures 100, 300, and 500 torr with $\mathrm{CH}_{4}$ as feedstock and background gas.
The foremost observed spectral lines are associated with singly ionized carbon ions (CII), and maximum ionic state for carbon ions is detected at +3 . The processed recorded spectra from arc plasma for different applied conditions with selected peaks are shown in Figures 1(a)-1(c).

The carbon arc plasma temperature for different applied experimental conditions are determined by Boltzmann intensity ratio method [21] as given in (1) using relative intensities of spectral lines emitted from the carbon species in arc plasma:

$$
T=-\frac{E_{i}-E_{m}}{k \ln \left(I_{i j} \lambda_{i j} A_{m n} \omega_{m} / I_{m n} \lambda_{m n} A_{i j} \omega_{i}\right)},
$$

where " $T$ " is the plasma temperature, $E_{i}$ and $E_{m}$ are the higher level energies of two different transitions of the same ionization state as either CII or CIII, $\lambda_{i j}$ and $\lambda_{m n}$ are the emitted wavelengths, $A_{i j}$ and $A_{m n}$ are the transition probabilities of higher level, $\omega_{i}$ and $\omega_{m}$ are the degeneracies, $I_{i j}$ and $I_{m n}$ are the intensities of emitted wavelengths, and $k$ is the Boltzmann constant.

The plasma densities under different conditions are determined by Saha equation [21] given as

$$
n_{e}=\frac{2\left(2 \pi m_{e} K T\right)^{3 / 2}}{h^{3}} \frac{I^{i} \lambda^{i} A^{i+1} \omega^{i+1}}{I^{i+1} \lambda^{i+1} A^{i} \omega^{i}} e^{-\left(E^{i+1}-E^{i}+\chi_{i}\right) / k T},
$$

where $n_{e}$ is the plasma density, $m_{e}$ is the mass of electron, $T$ is the plasma temperature, $E^{i+1}$ and $E^{i}$ are the higher level energies of singly ionized carbon atom (CII) and neutral carbon atom (CI), respectively, $\chi^{i}$ is the first ionization energy of carbon, $\lambda^{i+1}$ and $\lambda^{i}$ are the emitted wavelengths by CII and CI species, $A^{i+1}$ and $A^{i}$ are the transition probabilities of higher level for CII and CI, $\omega^{i+1}$ and $\omega^{i}$ are the degeneracy of the higher energy levels for CII and CI, $I^{i+1}$ and $I^{i}$ are the intensities of emitted spectral lines, $h$ is the Plank's constant, and $k$ is the Boltzmann constant.

The measurements of plasma temperatures and densities are performed under the special circumstances of local thermodynamic equilibrium (LTE) tested according to Mcwhirter's criterion [21].

Figures 2(a) and 2(b) show the plasma temperature and density profiles, respectively, with respect to arc currents and the ambient pressures. The rise in plasma temperature is observed with increase in arc current as well as ambient pressure as shown in Figure 2(a). The minimum plasma temperature $0.41 \mathrm{eV}$ is estimated for arc current $50 \mathrm{~A}$ at pressure 100 torr, whereas maximum value $1.06 \mathrm{eV}$ is measured for arc current $90 \mathrm{~A}$ at pressure 500 torr. The plasma density profile also shows an increasing trend with increase in arc current and ambient pressure except for arc current $70 \mathrm{~A}$ at pressure 300 torr as given in Figure 2(b).

The minimum plasma density is observed at $3.77 \times 10^{3} / \mathrm{m}^{3}$ for arc current $50 \mathrm{~A}$ at pressure 100 torr, and maximum electron density $2 \times 10^{20} / \mathrm{m}^{3}$ is obtained for arc current $90 \mathrm{~A}$ at pressure 500 torr. The electron density profile trend is similar to the electron temperature profile for the applied experimental conditions. However, an anomaly is observed for conditions of arc current $70 \mathrm{~A}$ at ambient pressure 300 torr. 


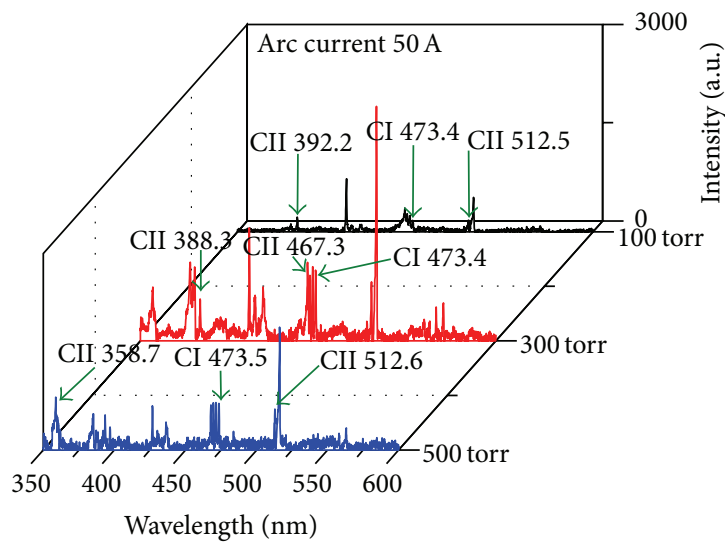

(a)

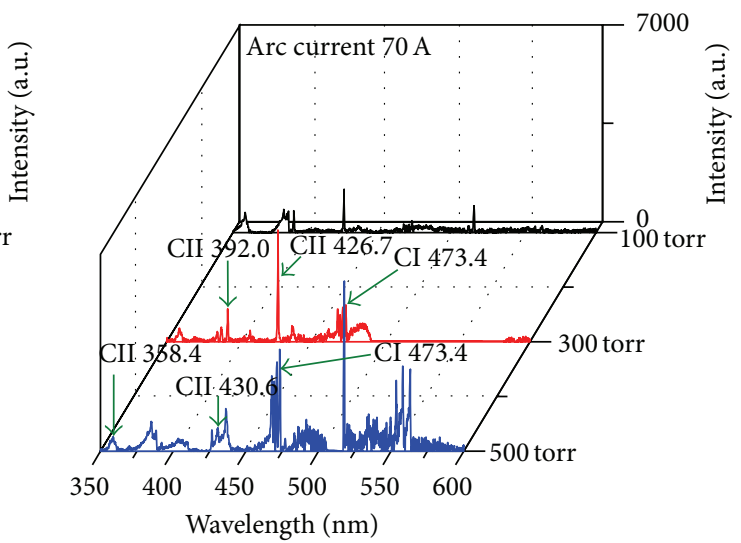

(b)

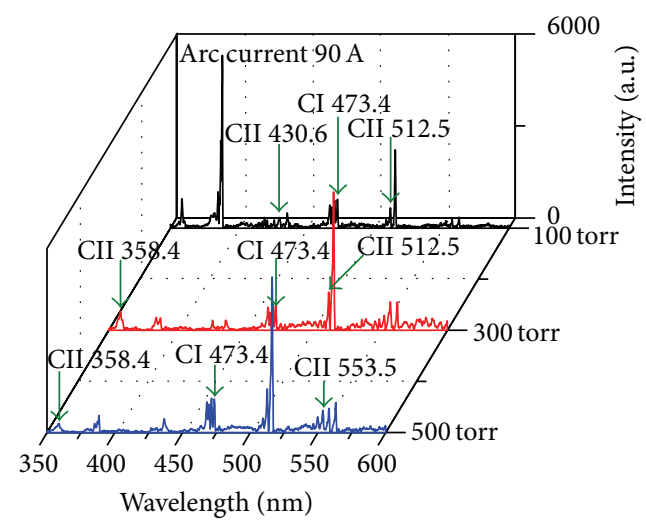

(c)

FIGURE 1: Optical emission spectra of arc plasma at pressure 100, 300, and 500 for arc current (a) $50 \mathrm{~A}$, (b) $70 \mathrm{~A}$, and (c) $90 \mathrm{~A}$.

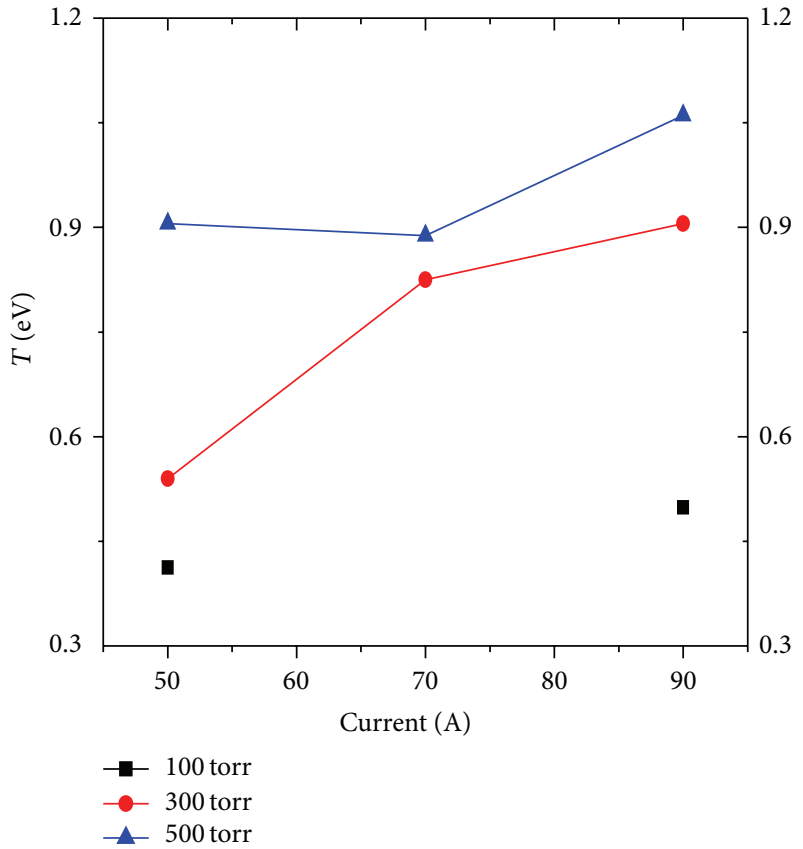

(a)

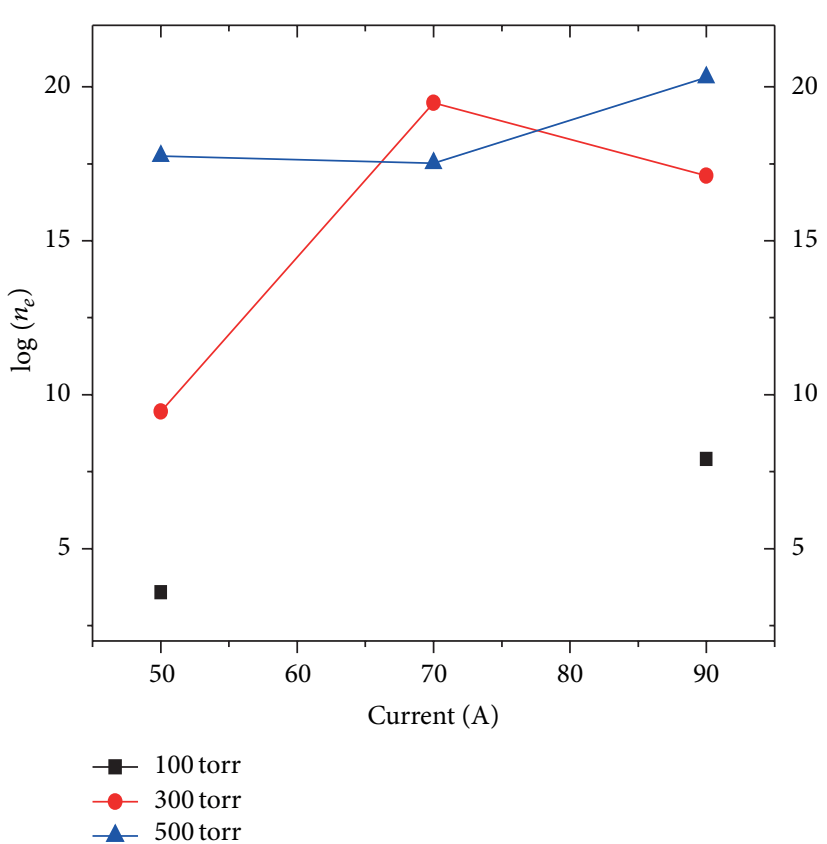

(b)

Figure 2: (a) Arc plasma temperature and (b) density for arc current 50, 70, and $90 \mathrm{~A}$ at pressure 100, 300, and 500 torr. 
The electron density at $70 \mathrm{~A}$ is higher than the density for arc current $90 \mathrm{~A}$ at the same pressure although the plasma temperature for $70 \mathrm{~A}$ is lower than $90 \mathrm{~A}$ at pressure 300 torr, which shows the relative abundance of the numbers of electron with average energy at these particular experimental conditions. By further increase in ambient pressure or arc current, the electron temperature is increased but the electron density decreased as depicted in Figures 2(a) and 2(b).

The rise in arc current increases energy flux at the anode surface and accelerates the evaporation of particles carrying high energy, which contribute to the increase of the temperature and density of plasma. Significant increase in electron temperature and density is observed for the increase in ambient pressure. The increase in plasma temperature and density with increase in ambient pressure can be explained on the basis of electron heating mechanisms with in plasma and the nature of residual gas. The capacitive discharge plasmas involve the two types of electron heating mechanisms, the stochastic heating, and ohmic (collision) heating. In stochastic heating mechanism, the electrons from the bulk interact with the oscillating electron sheath, transfer the momentum to sheath, and generate the stochastic heating at the sheath edge, while the ohmic heating is generated by the electronneutral collision in the bulk [22]. The stochastic heating mechanism is a dominant process at the low pressure, and increase in ambient pressure causes the transition of stochastic heating mechanism to the ohmic heating mechanism which enhances the plasma temperature. The increase in ambient pressure also changes the electron energy density function, which reduces the number of electrons carrying very high and very low energies, and increases the number of electrons with average energies [23].

The residence gas also has a significant effect on the plasma dynamics. During arc discharge, enough heat energy is produced even at $50 \mathrm{~A}$ arc current, which is sufficient to decompose the $\mathrm{CH}_{4}$ molecule into $\mathrm{C}$ and $\mathrm{H}_{2}$ [24]. Thus, the electrons form plasma carried sufficient energy to dissociate and ionize $\mathrm{CH}_{4}$ molecules in the plasma region due to inelastic electron collisions.

The decomposition of $\mathrm{CH}_{4}$ provides more carbon species with in the plasma volume which enhance the ohmic heating mechanism; that is, increase in ambient pressure of $\mathrm{CH}_{4}$ in reaction chamber provides more carbon species in the system and causes the transition of heating mechanism form stochastic heating mechanism to ohmic heating mechanism [22]. The increase in the chamber pressure also confined the plasma in certain region and led to the increase in heat flux at the anode surface which in turn enhances the anode ablation. The confinement of the plasma species in certain region between the electrodes gap causes the increase in electron temperature and density in smaller region [12]. The high ambient pressure also changes the electron energy density function, which reduces the number of electrons carrying very high and very low energies, and increases the number of electrons with average energies [23]. The large values of plasma density for arc current $70 \mathrm{~A}$ and $\mathrm{CH}_{4}$ ambient pressure 300 torr show that large number of electrons carrying same energy (i.e., average energy), and the dominant heating mechanism at these particular experimental conditions is ohmic heating mechanism.

The closed end MWCNT are observed in TEM micro graphs along with nanoparticles, amorphous carbon, and graphene stakes. The MWCNT with tube diameter in range $4-20 \mathrm{~nm}$, inner diameter in range of $<1-5 \mathrm{~nm}$, and length up to $650 \mathrm{~nm}$ are observed as shown in Figures 3-6. The interwall spacing is determined $0.34 \mathrm{~nm}$ near to graphite crystal interlayer spacing. In fully developed MWCNT, fewer defects are observed. The TEM micrographs of the synthesized samples for arc current $50 \mathrm{~A}$ at ambient pressure 100 torr are shown in Figures 3(a)-3(c). The bundles of MWCNT with inner diameter $<5 \mathrm{~nm}$ and outer diameters in the range of 5-18 $\mathrm{nm}$ along with graphitic nano particles are observed as given in Figure 3(b). However, some poorly aligned tube-like structures are also observed as shown in Figure 3(c).

Figures 4(a)-4(c) show the TEM images of sample prepared for arc current $50 \mathrm{~A}$ and pressure 500 torr. Under these experimental conditions, no tubule structures are found and the synthesized sample contains graphene stakes and amorphous carbon.

From Figures 3 and 4, it is found that, with increase in the $\mathrm{CH}_{4}$ ambient pressure from 100-500 torr for arc current $50 \mathrm{~A}$, a decrease in the growth of the nanotube structures and increase in the growth of graphene stakes and amorphous carbon are observed. The average distance between the stakes of graphene is observed at about $0.34 \mathrm{~nm}$ as shown in Figure 4(c).

The Figures 5 and 6 show the transmission electron microscopic images of the synthesized samples for arc current $90 \mathrm{~A}$ at ambient pressure 100 and 500 torr, respectively. The highly graphitized MWCNT structure with average diameter in the range of $6-20 \mathrm{~nm}$ and length $>600 \mathrm{~nm}$ with fewer defect along with graphene stakes and amorphous carbon is observed. However, the surface contamination of the nanotube is also seen for increase in the $\mathrm{CH}_{4}$ ambient pressure. The transmission electron microscopic analysis identifies increase in the growth of the carbon nanotube with increase in the $\mathrm{CH}_{4}$ ambient pressure from 100 to 500 torr. An improvement in the quality of nanotube structure in terms of defects and alignment is observed, with increase in applied arc current from 50 to $90 \mathrm{~A}$. However, for high ambient pressure 500 torr, increase in the growth of nanoparticles, graphene, and surface contamination of nanotube is also observed. The improvement in the structural quality of grown MWCNT at high arc current infers that the temperature of cathode surface plays important role and contributes towards the annealing of the tubular structures which in turn lead to formation of well-aligned MWCNT. For lower arc current $50 \mathrm{~A}$, increase in the ambient pressure from 100 to 500 torr reduces the growth of tubular structures and enhances the growth of nanoparticles and graphene stakes. However, for high arc current $90 \mathrm{~A}$, an increase in the $\mathrm{CH}_{4}$ ambient pressure leads to increase in the growth of MWCNT with relatively smaller inner diameter (as compared to lower arc current and ambient pressure) and carbon nanostructures.

The scanning microscopic images of synthesized materials for arc currents $50 \mathrm{~A}$, at ambient pressures 100, 300, 


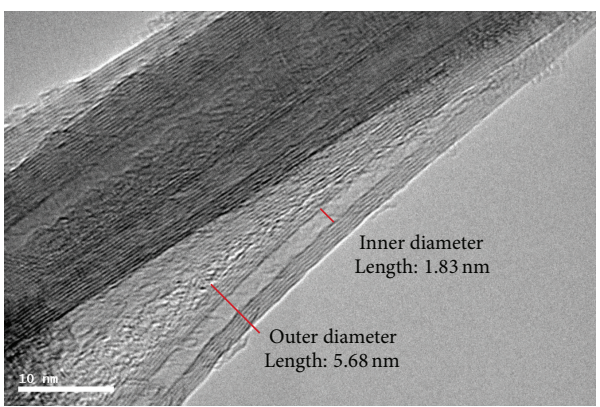

(a)

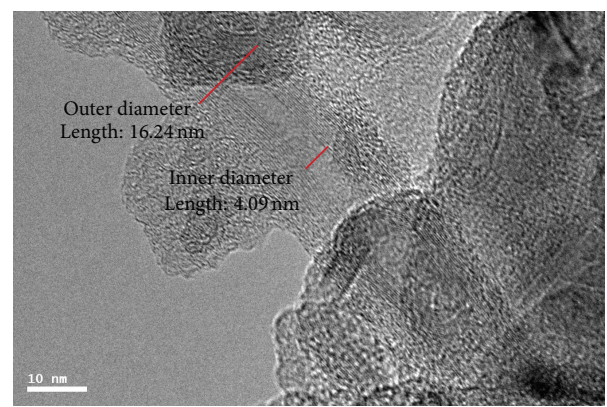

(b)

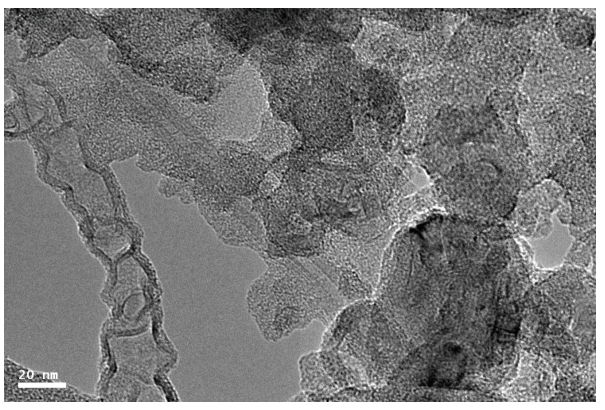

(c)

FIGURE 3: TEM micrographs of MWCNT synthesized for arc current $50 \mathrm{~A}$ at ambient pressure 100 torr.

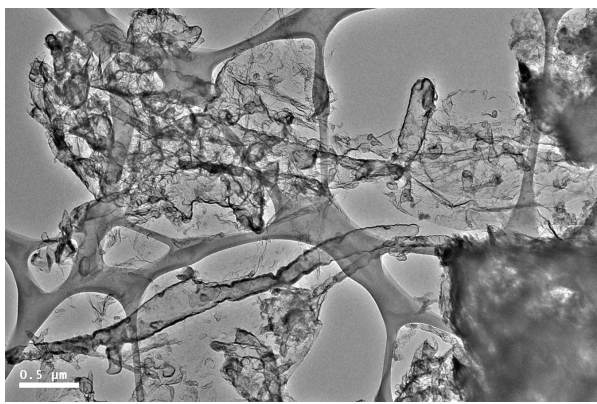

(a)

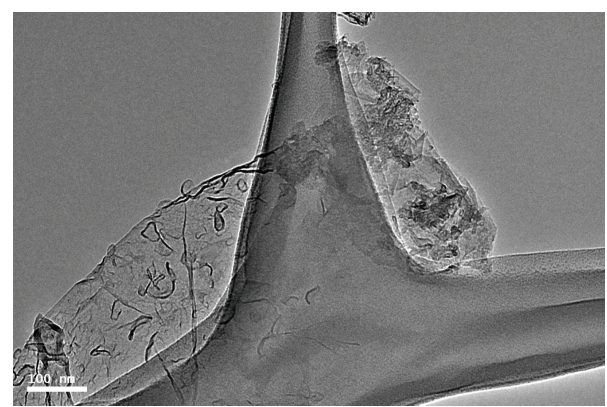

(b)

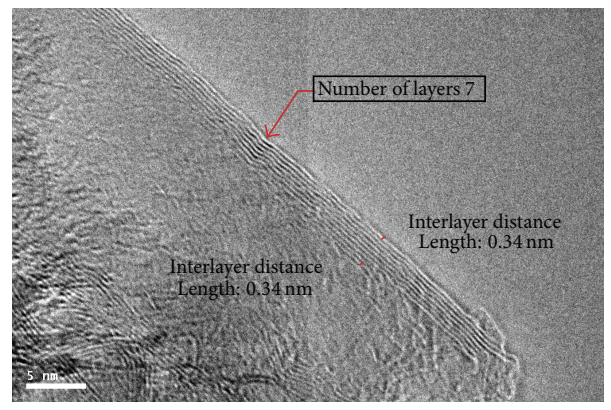

(c)

FIgURE 4: TEM micrographs of MWCNT synthesized for arc current $50 \mathrm{~A}$ at ambient pressure 500 torr.

and 500 torr, are shown in Figures $7(\mathrm{a})-7(\mathrm{c})$, respectively. The dense MWCNT along nanoparticles and amorphous carbon are observed. A decrease in the MWCNT density and increase in the amorphous structures are observed with increase in the ambient pressure from 100 to 500 torr.
The electron microscopic images of the sample material prepared for arc current $70 \mathrm{~A}$ at pressure 100, 300, and 500 torr are given in Figures $8(\mathrm{a})-8(\mathrm{c})$, respectively. The MWCNT along with the carbon nanoparticle, amorphous carbon, and graphene stakes are observed. 


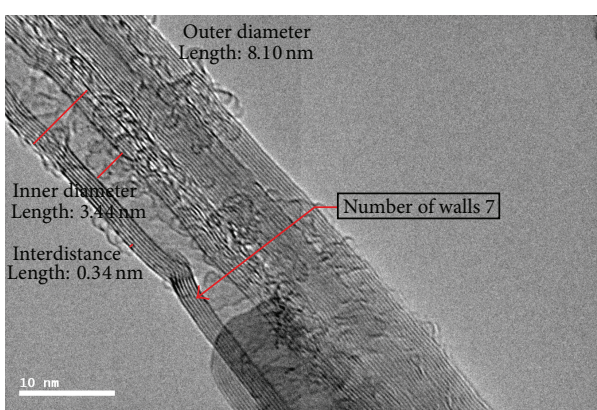

(a)

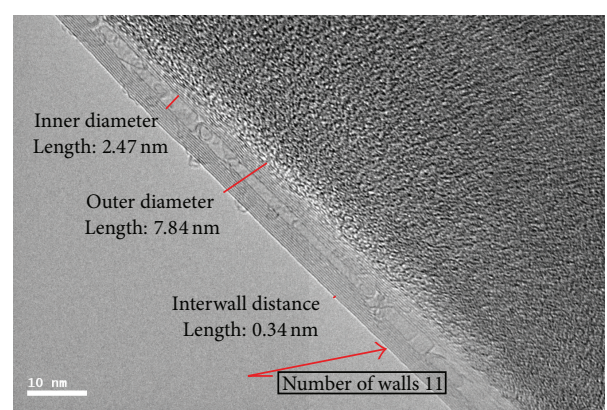

(b)

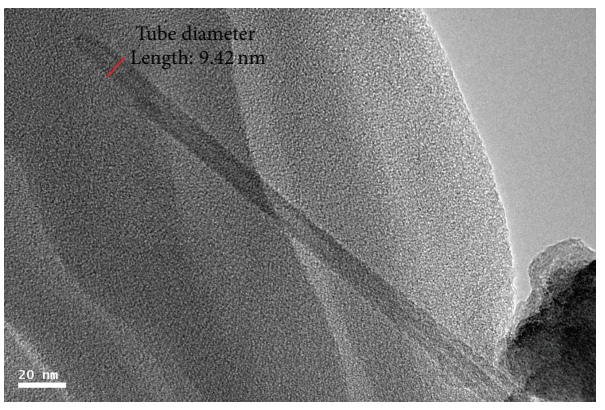

(c)

FIGURE 5: TEM micrographs of MWCNT synthesized for arc current $90 \mathrm{~A}$ at ambient pressure 100 torr.

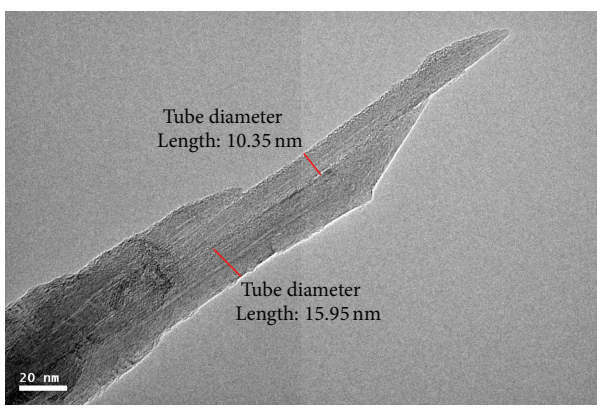

(a)

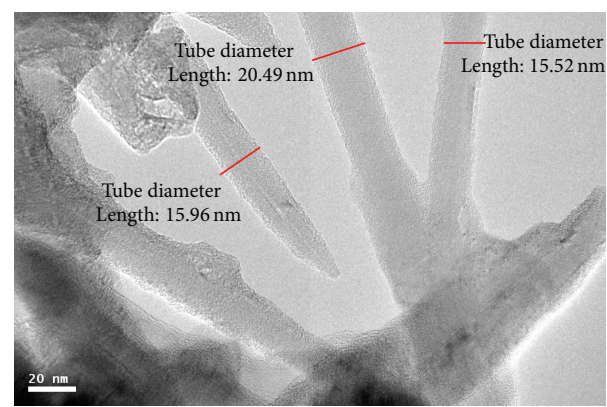

(b)

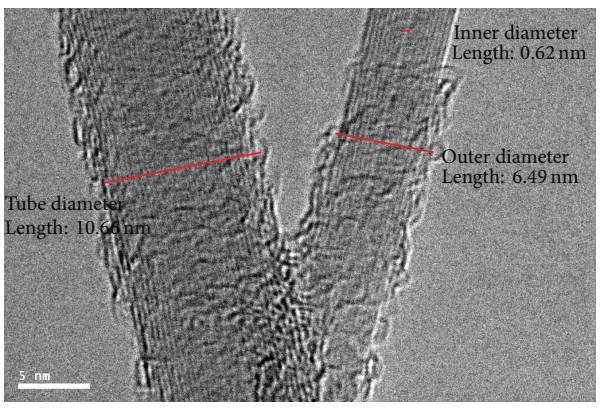

(c)

FIGURE 6: TEM micrographs of MWCNT synthesized for arc current $90 \mathrm{~A}$ at ambient pressure 500 torr.

For arc current $70 \mathrm{~A}$, the increase in the ambient from 100 to 500 torr causes an increase in the density of nanotube and nanostructures. The high density MWCNT and amorphous carbon are found for arc current $90 \mathrm{~A}$ at ambient pressure 100, 300, and 500 as shown in Figures 9(a)-9(c). For arc current
$90 \mathrm{~A}$, an improvement in the structures of the nanotube and increase in the nanotube density is detected with rise in ambient pressure of $\mathrm{CH}_{4}$ gas from 100 to 500 torr. Besides this, increase in the growth of graphene structures is also observed. The scanning electron microscopic analysis reveals 


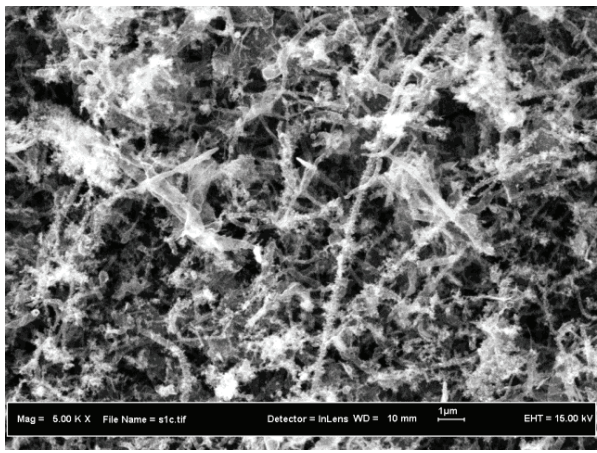

(a)

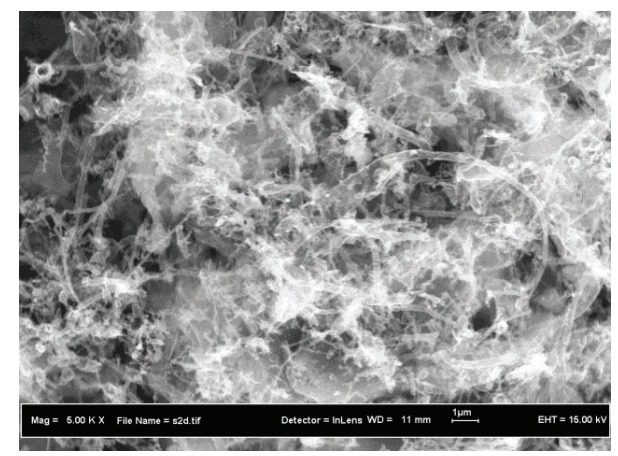

(b)

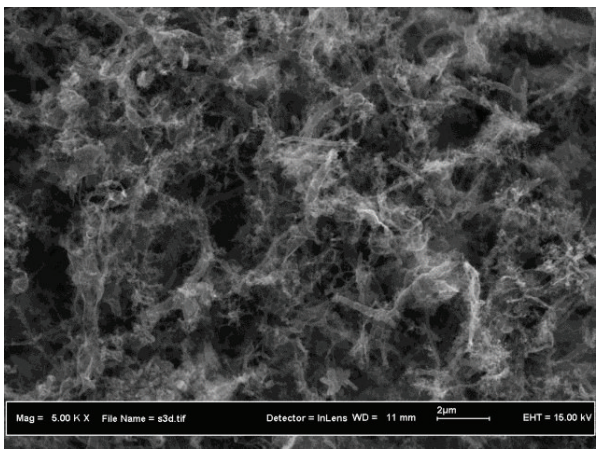

(c)

FIGURE 7: Scanning electron microscopic images of MWCNT synthesized for arc current $50 \mathrm{~A}$ at ambient pressures (a) 100 torr, (b) 300 torr, and (c) 500 torr.

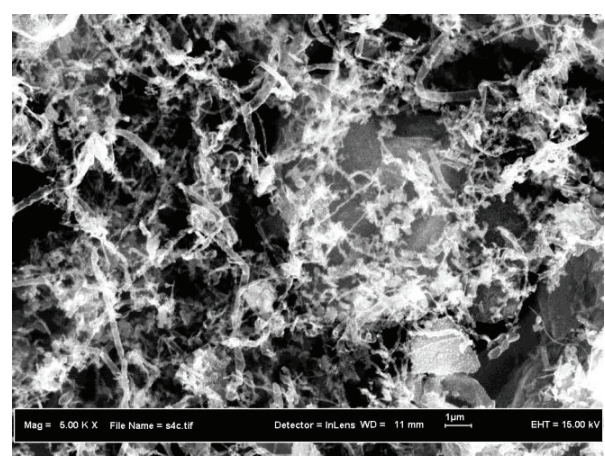

(a)

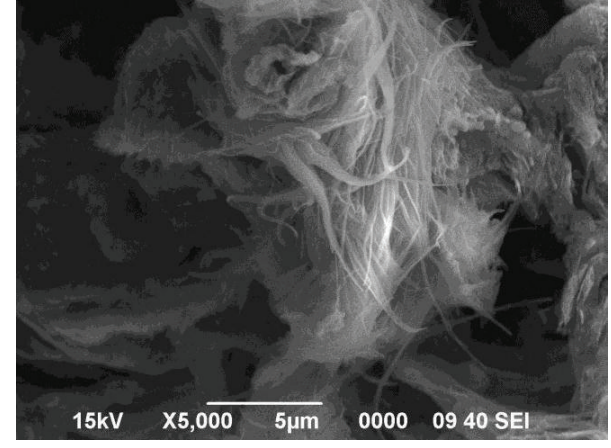

(b)

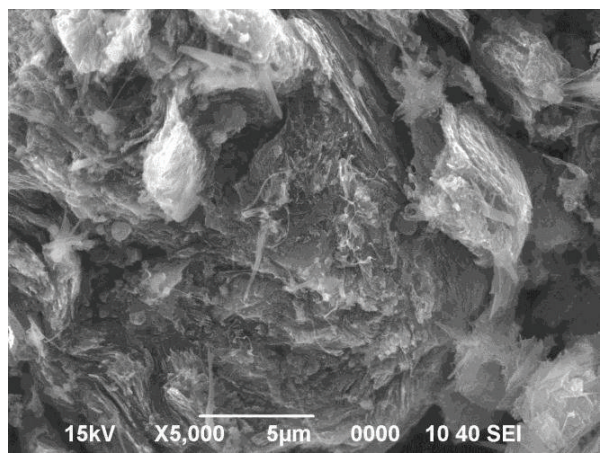

(c)

FIGURE 8: Scanning electron microscopic images of MWCNT synthesized for arc current $70 \mathrm{~A}$ at ambient pressures (a) 100 torr, (b) 300 torr, and (c) 500 torr. 


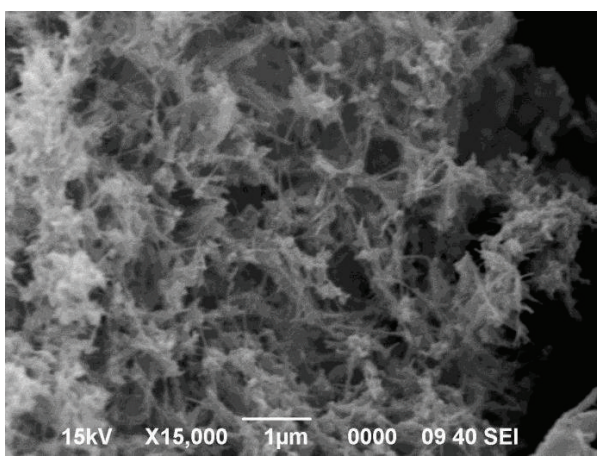

(a)

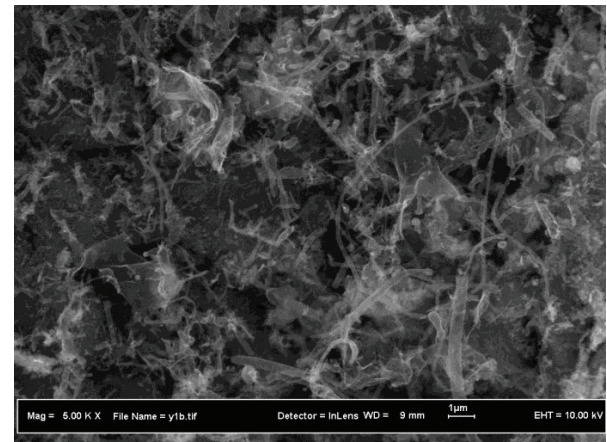

(b)

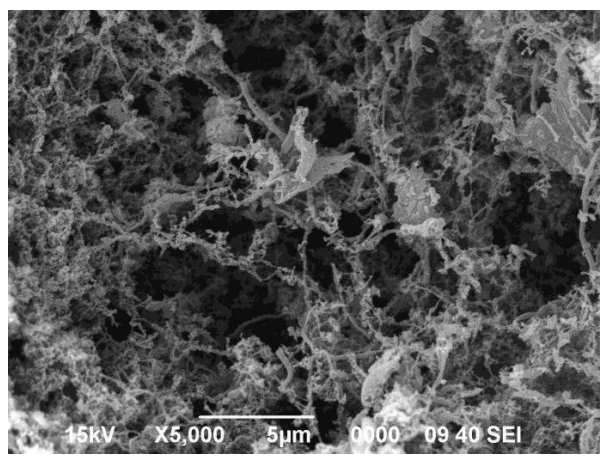

(c)

FiguRE 9: Scanning electron microscopic images of MWCNT synthesized for arc current $90 \mathrm{~A}$ at ambient pressures (a) 100 torr, (b) 300 torr, and (c) 500 torr.

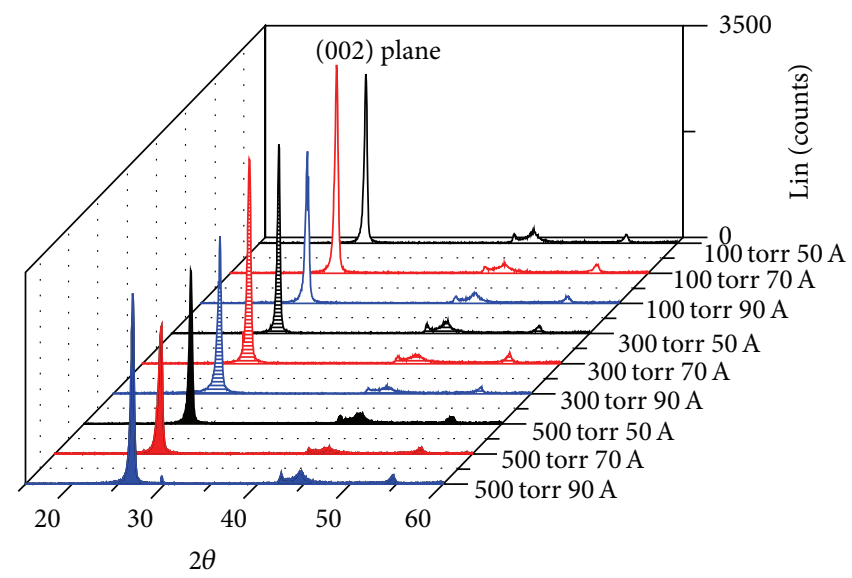

FIGURE 10: XRD spectra of synthesized CNTs for arc current 50, 70, and $90 \mathrm{~A}$ at ambient pressure 100, 300, and 500 torr.

that increase in $\mathrm{CH}_{4}$ ambient pressure and arc current causes an improvement in structure quality, decrease in inner tube diameter, increase in tube length, and growth rate of MWCNT. However, high ambient pressure enhances the growth of graphene flaks and nanoparticles as observed in TEM micrographs.

Figure 10 shows the XRD spectra of the synthesized MWCNT for arc currents 50, 70, and 90 at ambient pressures 100,300 , and 500 torr. A strong peak at position $\sim 26.5^{\circ}$ and relatively weak peaks at positions $\sim 42.5^{\circ}, \sim 44.5^{\circ}$, and $\sim 54.5^{\circ}$ for angle $2 \theta$ associated with planes (002), (100), (101), and (004) [25], respectively are detected for each recorded XRD spectra. The strong peaks at $\sim 26.5^{\circ}$ corresponding to the (002) graphite plane show the presence of graphitized structures.

Figures $11(\mathrm{a})$ and $11(\mathrm{~b})$ show the shift in the angle $2 \theta$ and variation in FWHM, respectively, for peak corresponding to (002) plane with respect to applied arc current and $\mathrm{CH}_{4}$ ambient pressures. The downshifts in peak associated with (002) plane towards the low angle with increase in ambient pressure from 100 to 500 torr show the increase in 


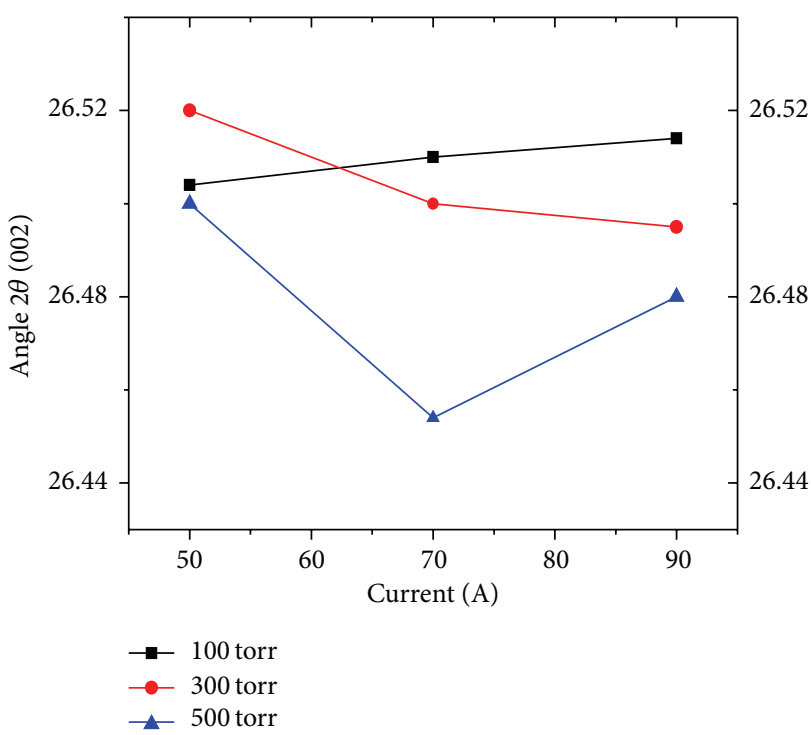

(a)

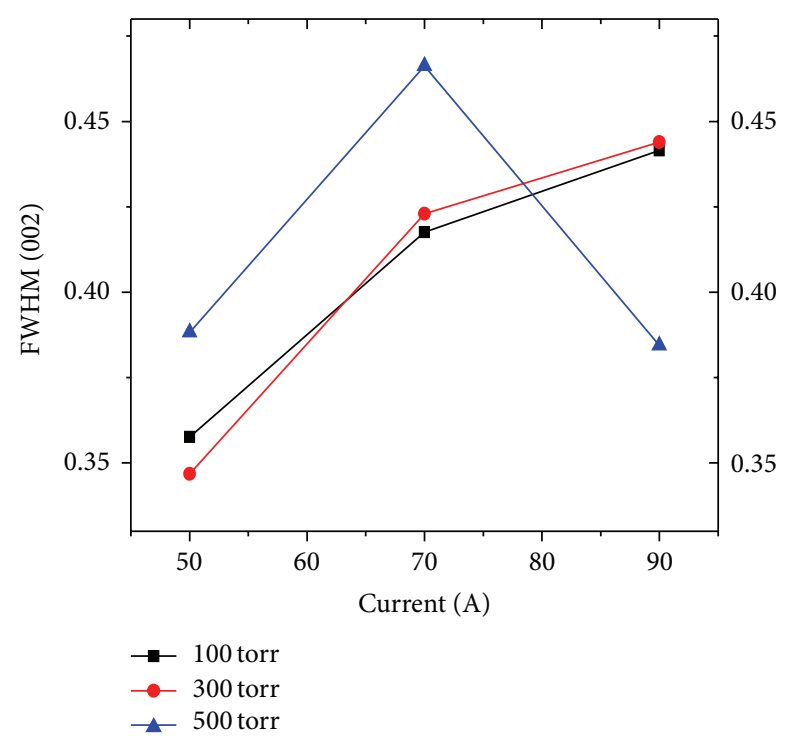

(b)

FIGURE 11: (a) Position of angle $2 \theta$ and variation in (b) FWHM of the peak for plane (002) of synthesized MWCNT at different experimental conditions.

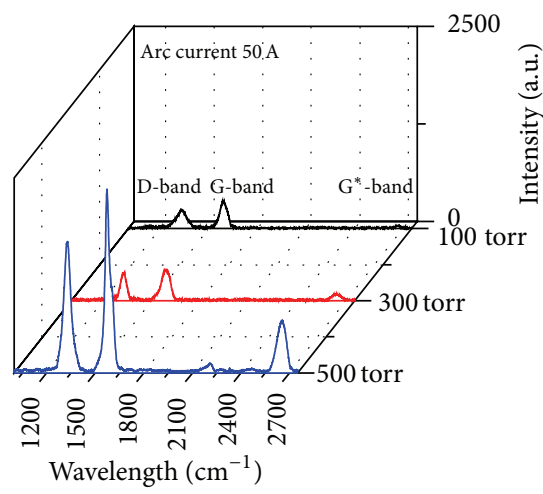

(a)

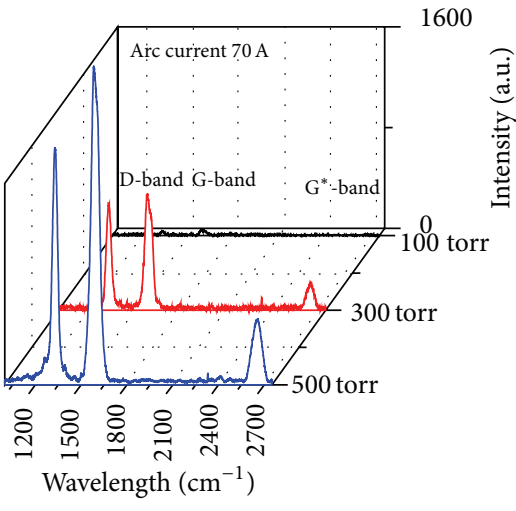

(b)

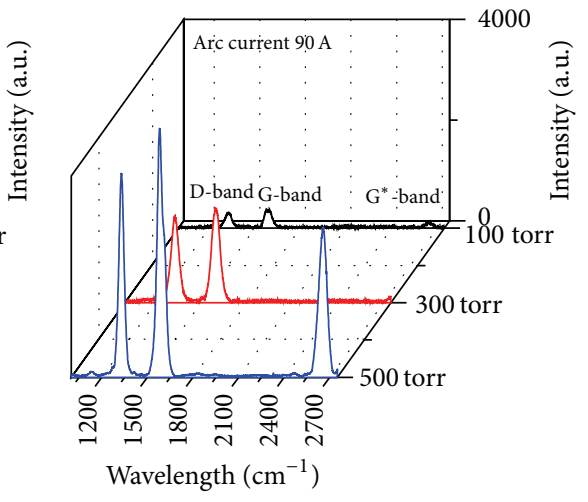

(c)

Figure 12: Raman spectra of synthesized MWCNT at pressure 100, 300, and 500 torr for arc currents (a) 50 A, (b) 70 A, and (c) 90 A.

growth of carbon nanotube and graphitic nanostructures. The estimated values for d-spacing are in range of 0.336 $0.340 \mathrm{~nm}$ which are in agreement with the TEM microscopic measurements. An increase in the line width of (002) peak is observed with increase in the ambient pressure as well as arc current as shown in Figure 11(b). The downshift and broadening in the peak corresponding to (002) plane show the increase in the growth of carbon nanotube and structures with increase in the ambient pressure.

The spectral lines in region of $1325-1335 \mathrm{~cm}^{-1}, 1570-$ $1600 \mathrm{~cm}^{-1}$, and $2630-2680 \mathrm{~cm}^{-1}$ named as D-line, G-line and $\mathrm{G}^{*}$-line [26, 27], respectively, are observed in Raman spectra of MWCNT samples synthesized at different experimental conditions as shown in Figures 12(a)-12(c). The strong Glines in the region of $1570-1600 \mathrm{~cm}^{-1}$ in all captured spectra identify the presence of highly graphitized graphitic structures in the synthesized samples. An increase in the intensity of the G-line with increase in the ambient pressure and arc current shows an increase in the growth and improvement in the structure of MWCNT.

The high intensity D-lines in the region of $1325-1335 \mathrm{~cm}^{-1}$ refers to the presence of ill-organized graphitic structures. However, D-line is also considered as intrinsic feature of MWCNT Raman spectrum as the curved nature of the graphite sheets leads to the increase in the intensity of Dline due to enhancement in the electron-phonon coupling [28]. From Figures 12(a)-12(c), it is observed that the intensity of D-line is increased with increase in ambient pressure of $\mathrm{CH}_{4}$ gas and arc current. The increase in D-line intensity with increase in ambient pressure and arc current can be attributed to the presence of defective structure and increase in the growth of MWCNT with smaller diameter and carbon nanostructures. The $\mathrm{G}^{*}$-band shows the presence of the crystalline graphite in the form of one or multilayers of 


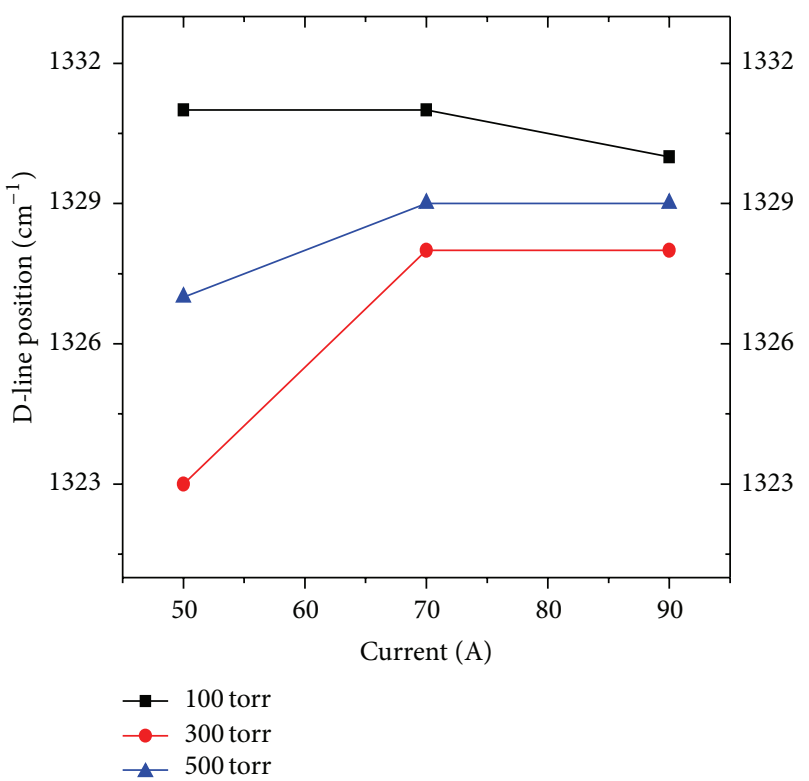

(a)

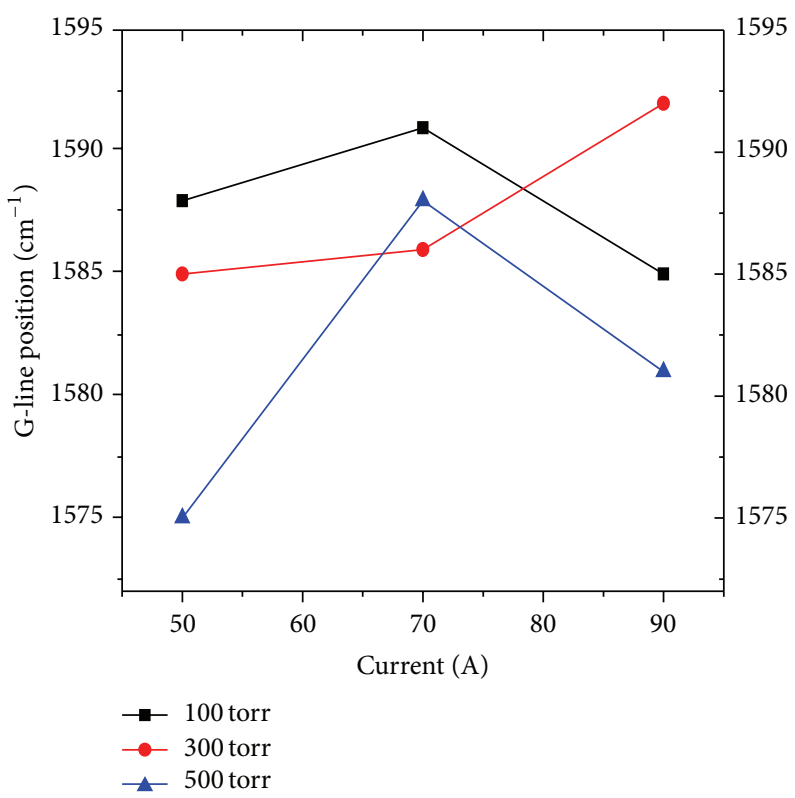

(b)

FIGURE 13: Shift in (a) D-line and (b) G-line with respect to arc current and ambient pressure for synthesized MWCNT.

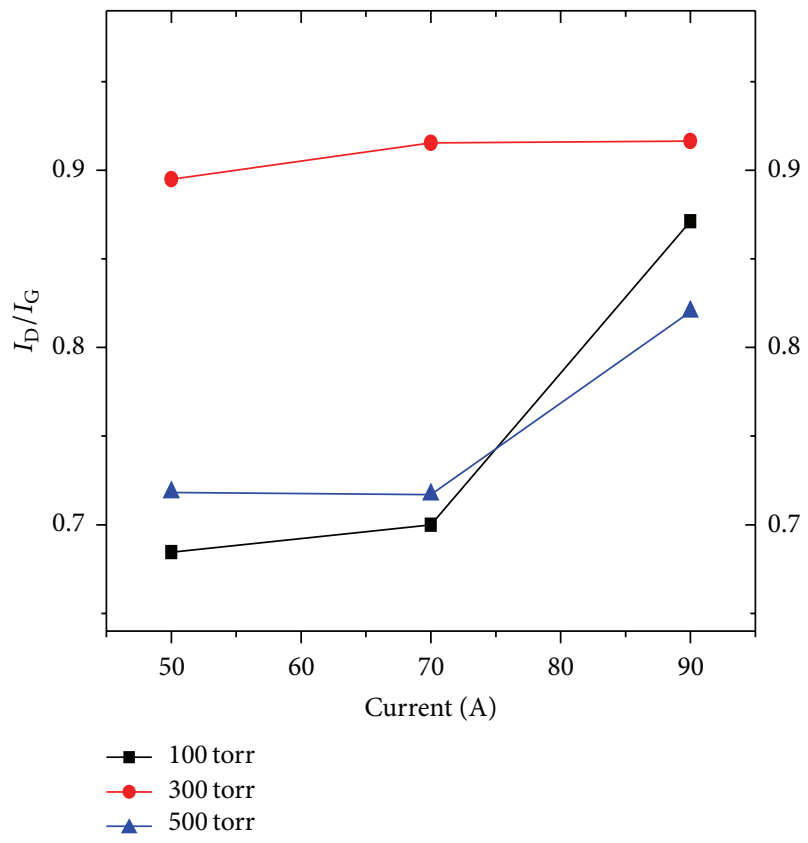

(a)

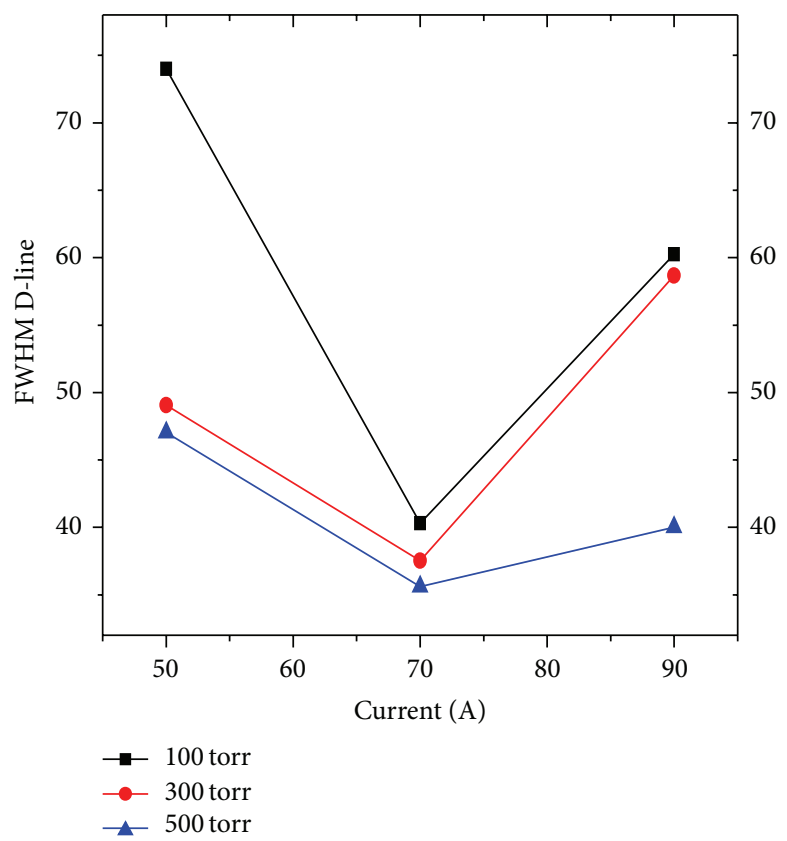

(b)

FIGURE 14: Variation in (a) $I_{\mathrm{D}} / I_{\mathrm{G}}$ and (b) FWHM of D-lines for the MWCNT prepared at different experimental conditions.

graphene sheets [29] in the grown samples as observed in TEM microscopy. Thus, the Raman spectrographs show the presence of the MWCNT in all synthesized samples along with graphite crystallites, nanostructures, and graphene. An increase in the relative intensity of the $\mathrm{G}^{*}$-line with rise in the ambient pressure and arc current as depicted in Figures 12(a)-12(c) illustrates the increase in the growth of graphene stakes [30] at high pressure.
The shift in D-lines and G-lines with respect to ambient pressure and arc current is shown in Figures 13(a) and 13(b), respectively. A downshift in D and G-line positions with increase in the $\mathrm{CH}_{4}$ ambient pressure and little upshift with increase in arc current is observed. The downshift in D-line as shown in Figure 13(a) with increase in ambient pressure shows rise in the growth of MWCNT with small diameter. The position of $\mathrm{D}$-line in the spectrum strongly depends 


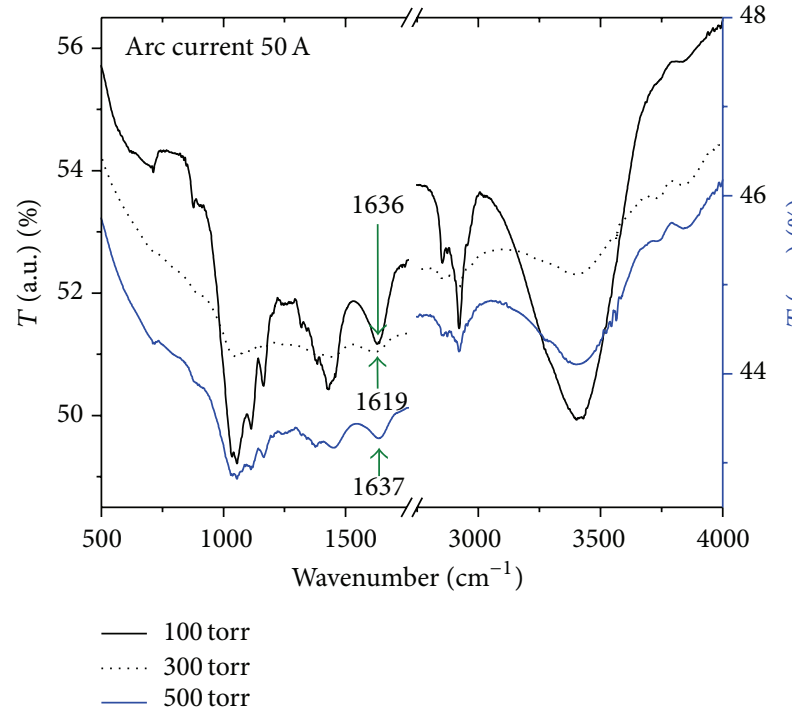

(a)

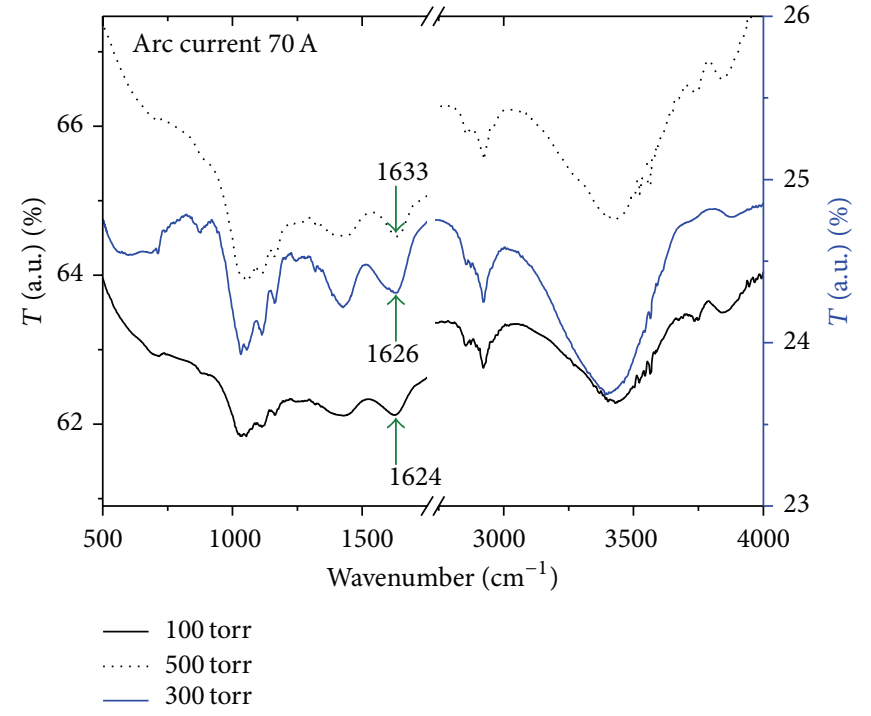

(b)

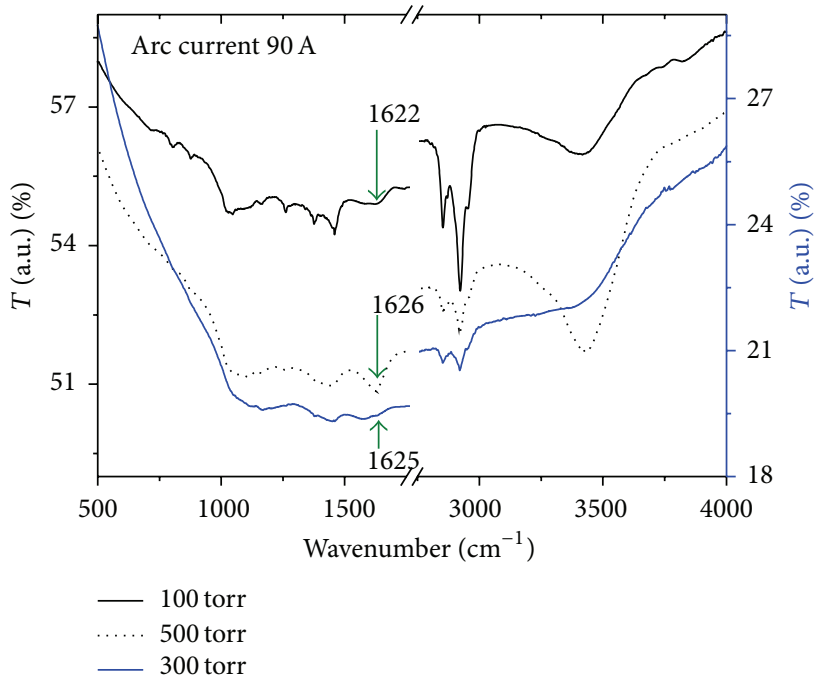

(c)

FIGURE 15: FTIR spectra of synthesized MWCNTs for arc currents 50, 70, and $90 \mathrm{~A}$ at pressures (a) 100 torr, (b) 300 torr, and (c) 500 torr.

on the laser excitation energy, and the location of D-line for MWCNTs can be expressed as $\omega_{\mathrm{D}}=1285+26.5 E_{\text {laser }}$ [28]. During Raman analysis the value of $E_{\text {Laser }}$ is $1.95 \mathrm{eV}$ and thus the position of D-line should be at $1335 \mathrm{~cm}^{-1}$, which is in agreement with observed peak position in Raman spectra. The downshift of G-line as shown in Figure 13(b) with increase in ambient pressure shows the improvement in the nanotube structure quality as well as enhancement in the growth of graphene sheets. The upshift in the D and G-lines at ambient pressure 500 torr can be attributed to formation of graphene due to presence of hydrogen which prevents the closure of the nanostructures and leads to the formation of graphene flakes [8]. The position of G-lines in the spectral region $1570-1590 \mathrm{~cm}^{-1}$ [31] shows the semiconductor nature of synthesized MWCNT. Figure 14(a) presents the variation in the intensity ratio $\left(I_{\mathrm{D}} / I_{\mathrm{G}}\right)$ of D-line to G-line with respect to arc current and ambient pressure. The high values of $I_{\mathrm{D}} / I_{\mathrm{G}}$ show the presence of disorder structures, amorphous carbon, nanocrystallites, and graphene stacks in synthesized samples. An increase in the $I_{\mathrm{D}} / I_{\mathrm{G}}$ is observed with increase in ambient pressure which is referred to the increase in the growth of graphitic structures with rise in ambient pressure.

A decrease in the line width of the D-band is observed with increases in the ambient pressure as given in Figure 14(b). The line width of the D-bands is found in the range of $30-60 \mathrm{~cm}^{-1}$, which shows the presence of crystallite graphite and MWCNT. The line width of the D-band is large for the carbon nanotubes with small diameter $<20 \mathrm{~nm}$ and then decreases slightly for the higher diameter MWCNT [31]. From the Raman spectral analysis, an improvement in the structure quality and increase in the growth of the graphite crystallite and graphene stakes are 


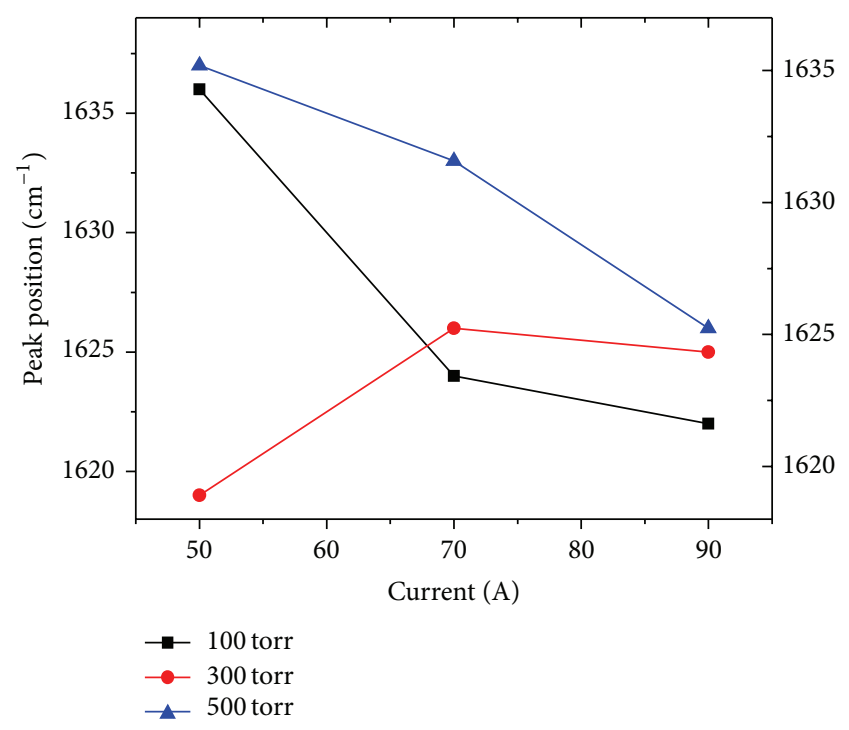

FIGURE 16: Shift in peak at position $1630 \mathrm{~cm}^{-1}$ with respect to arc currents and ambient pressures.

observed with increase in the $\mathrm{CH}_{4}$ pressure and applied arc current. The downshift in D and G-lines and broadening in D-line with increase in the ambient pressure and arc current show increase in the growth and improvement in structural quality of grown MWCNT. However, the high $I_{\mathrm{D}} / I_{\mathrm{G}}$ values show that the synthesized samples consist of graphite crystallites, carbon nanostructures, and amorphous carbon.

The FTIR spectra of synthesized MWCNT at different ambient pressures and arc currents are shown in Figures 15(a)-15(c), respectively. In FTIR spectra of synthesized samples, the spectral lines in the following ranges 3740-3840, $3400,2920,2850,1630,1560-1580,1420-1460^{1}, 1380,1160-$ 1170,1110 , and $1050 \mathrm{~cm}^{-1}$ are detected. No spectral line is observed in the range of $1750-2750 \mathrm{~cm}^{-1}$. In FTIR spectra of MWCNT, the peaks in the region of $1560-1580 \mathrm{~cm}^{-1}$ and at $1460 \mathrm{~cm}^{-1}$ represent the $\mathrm{C}-\mathrm{C}$ vibrational modes associated with the carbon skeleton of the MWCNT [3235]. The vibration mode at $\sim 1620 \mathrm{~cm}^{-1}$ is referred to the presence of $\mathrm{C}=\mathrm{C}$ group [36], which shows the presence of the $\mathrm{sp}^{3}$ characterization. The broadening, downshift, and decrease in peaks height at position $1630 \mathrm{~cm}^{-1}$ associated with $\mathrm{C}=\mathrm{C}$ stretching mode is observed with increase in ambient pressure from 100 to 500 torr. However, broadening and a little upshift in peaks at position $1630 \mathrm{~cm}^{-1}$ are found with increase in arc current from 50 to $90 \mathrm{~A}$ as shown in Figure 16.

The shift in peak at position $1630 \mathrm{~cm}^{-1}$ with respect to arc current is small as compared to ambient pressure. Ten to $20 \mathrm{~cm}^{-1}$ downshift in peak positions is detected with increase in the ambient pressure from 100 to 500 torr, and $5-10 \mathrm{~cm}^{-1}$ upshift is spotted with increase in the arc current 50-90 A as depicted in Figure 16. According to microscopic analysis of the synthesized samples, an increase in the growth of the graphene stakes and MWCNT with smaller diameter is observed with increase in $\mathrm{CH}_{4}$ ambient pressure. Thus, it can be inferred that the downshift and broadening in the peak at position $1630 \mathrm{~cm}^{-1}$ associated with $\mathrm{C}=\mathrm{C}$ stretching mode with increase in the arc current indicates the increase in the growth of carbon nanoparticle and graphene stakes. And upshift in the peak at position $1630 \mathrm{~cm}^{-1}$ with rise in $\mathrm{CH}_{4}$ ambient pressure refers to increase in the growth of nanotubular structures.

\section{Conclusion}

The MWCNT are synthesized by arc discharge technique in presence of the $\mathrm{CH}_{4}$ gas for different ambient pressures and arc currents. The plasma temperature and density are estimated by optical emission spectroscopy. An increase in plasma temperature and density is observed, with increase in applied arc current as well as ambient pressure. The microscopic, spectroscopic, and XRD analyses of synthesized MWCNT infer significant improvement in MWCNT in terms of growth, quality, and size with increase in the applied arc current and $\mathrm{CH}_{4}$ ambient pressure. It is found that the high ambient pressure leads to increase in the growth of MWCNT with small inner diameter. However, the synthesis of the carbon nanostructures and graphene stakes is also increased at high ambient pressure. An improvement in the structure quality of grown MWCNT is observed with increase in the arc current from 50 to $90 \mathrm{~A}$. At high arc current the walls of grown MWCNT are well aligned, highly straight, and fully developed. The high temperature of cathode surface for large value of arc current provides sufficient heat to anneal defective sites of the tubes and leads to formation of properly aligned MWCNT.

\section{References}

[1] C. Journet, M. Picher, and V. Jourdain, "Carbon nanotube synthesis: from large-scale production to atom-by-atom growth," Nanotechnology, vol. 23, no. 14, Article ID 142001, 2012.

[2] H. C. Chang, C. C. Li, S. F. Jen et al., "All-carbon field emission device by direct synthesis of graphene and carbon nanotube," Diamond and Related Materials, vol. 31, pp. 42-46, 2012.

[3] E. T. Thostenson, Z. Ren, and T.-W. Chou, "Advances in the science and technology of carbon nanotubes and their composites: a review," Composites Science and Technology, vol. 61, no. 13, pp. 1899-1912, 2001.

[4] A. Jorio, G. Dresselhaus, and M. S. Dresselhaus, Carbon Nanotubes: Advanced Topics in the Synthesis, Structure, Properties and Applications, Springer, Berlin, Germany, 2008.

[5] S. Iijima, "Helical microtubules of graphitic carbon," Nature, vol. 354, no. 6348, pp. 56-58, 1991.

[6] S. Hofmann, C. Ducati, J. Robertson, and B. Kleinsorge, "Lowtemperature growth of carbon nanotubes by plasma-enhanced chemical vapor deposition," Applied Physics Letters, vol. 83, no. 1, pp. 135-137, 2003.

[7] T. Guo, P. Nikolaev, A. Thess, D. T. Colbert, and R. E. Smalley, "Catalytic growth of single-walled manotubes by laser vaporization," Chemical Physics Letters, vol. 243, no. 1-2, pp. 49-54, 1995.

[8] M. Jinno, S. Bandow, and Y. Ando, "Multiwalled carbon nanotubes produced by direct current arc discharge in hydrogen gas," Chemical Physics Letters, vol. 398, no. 1-3, pp. 256-259, 2004. 
[9] Z. Wang, N. Li, Z. Shi, and Z. Gu, "Low-cost and largescale synthesis of graphene nanosheets by arc discharge in air," Nanotechnology, vol. 21, no. 17, Article ID 175602, 4 pages, 2010.

[10] J. P. Metters and C. E. Banks, "Electrochemical utilisation of chemical vapour deposition grown carbon nanotubes as sensors," Vacuum, vol. 86, no. 5, pp. 507-519, 2012.

[11] Y. A. Kim, H. Muramatsu, T. Hayashi, and M. Endo, "Catalytic metal-free formation of multi-walled carbon nanotubes in atmospheric arc discharge," Carbon, vol. 50, no. 12, pp. 45884595, 2012.

[12] G. Tan and T. Mieno, "Experimental and numerical studies of heat convection in the synthesis of single-walled carbon nanotubes by arc vaporization," Japanese Journal of Applied Physics, vol. 49, no. 4, Article ID 045102, 6 pages, 2010.

[13] X. Cai, H. Cong, and C. Liu, "Synthesis of vertically-aligned carbon nanotubes without a catalyst by hydrogen arc discharge," Carbon, vol. 50, no. 8, pp. 2726-2730, 2012.

[14] S. Farhat, M. L. de la Chapelle, A. Loiseau et al., "Diameter control of single-walled carbon nanotubes using argon-helium mixture gases," The Journal of Chemical Physics, vol. 115, article 6752, 2001.

[15] G. Xing, S.-L. Jia, and Z.-Q. Shi, "The production of carbon nano-materials by arc discharge under water or liquid nitrogen," New Carbon Materials, vol. 22, no. 4, pp. 337-341, 2007.

[16] H. Lange, M. Sioda, A. Huczko, Y. Q. Zhu, H. W. Kroto, and D. R. M. Walton, "Nanocarbon production by arc discharge in water," Carbon, vol. 41, no. 8, pp. 1617-1623, 2003.

[17] Y. Jiang, H. Wang, X. F. Shang, Z. H. Li, and M. Wang, "Influence of $\mathrm{NH}_{3}$ atmosphere on the growth and structures of carbon nanotubes synthesized by the arc-discharge method," Inorganic Materials, vol. 45, no. 11, pp. 1237-1239, 2009.

[18] J. Prasek, J. Drbohlavova, J. Chomoucka et al., "Methods for carbon nanotubes synthesis-review," Journal of Materials Chemistry, vol. 21, no. 40, pp. 15872-15884, 2011.

[19] J. Kong, A. M. Cassell, and H. Dai, "Chemical vapor deposition of methane for single-walled carbon nanotubes," Chemical Physics Letters, vol. 292, no. 4-6, pp. 567-574, 1998.

[20] I. Abdullahi, N. Sakulchaicharoen, and J. E. Herrera, "A mechanistic study on the growth of multi-walled carbon nanotubes by methane decomposition over nickel-alumina catalyst," Diamond and Related Materials, vol. 23, pp. 76-82, 2012.

[21] R. Noll, Laser-Induced Breakdown Spectroscopy: Fundamentals and Applications, Springer, Berlin, Germany, 2012.

[22] S. Sharma and M. Turner, "Study of stochastic heating in single frequency capacitive discharges," in Proceedings of the 37th EPS Conference on Plasma Physics, p. P1.323, Dublin, Ireland, June 2010.

[23] F. J. Gordillo-Vázquez, M. Camero, and C. Gómez-Aleixandre, "Spectroscopic measurements of the electron temperature in low pressure radiofrequency $\mathrm{Ar} / \mathrm{H}_{2} / \mathrm{C}_{2} \mathrm{H}_{2}$ and $\mathrm{Ar} / \mathrm{H}_{2} / \mathrm{CH}_{4}$ plasmas used for the synthesis of nanocarbon structures," Plasma Sources Science and Technology, vol. 15, no. 1, pp. 42-51, 2006.

[24] K. Shimotani, K. Anazawa, H. Watanabe, and M. Shimizu, "New synthesis of multi-walled carbon nanotubes using an arc discharge technique under organic molecular atmospheres," Applied Physics A, vol. 73, no. 4, pp. 451-454, 2001.

[25] Y. Sun, S. Yang, G. Sheng, Z. Guo, and X. Wang, "The removal of $\mathrm{U}(\mathrm{VI})$ from aqueous solution by oxidized multiwalled carbon nanotubes," Journal of Environmental Radioactivity, vol. 105, pp. 40-47, 2012.
[26] T. Belin and F. Epron, "Characterization methods of carbon nanotubes: a review," Materials Science and Engineering B, vol. 119, no. 2, pp. 105-118, 2005.

[27] F. Liang, T. Shimizu, M. Tanaka et al., "Selective preparation of polyhedral graphite particles and multi-wall carbon nanotubes by transferred arc under atmospheric pressure," Diamond and Related Materials, vol. 30, pp. 70-76, 2012.

[28] J. Sengupta and C. Jacob, "The effect of Fe and Ni catalysts on the growth of multiwalled carbon nanotubes using chemical vapor deposition," Journal of Nanoparticle Research, vol. 12, no. 2, pp. 457-465, 2010.

[29] L. G. Cançado, K. Takai, T. Enoki et al., "Measuring the degree of stacking order in graphite by Raman spectroscopy," Carbon, vol. 46, no. 2, pp. 272-275, 2008.

[30] M. Endo, Y. A. Kim, T. Takeda et al., "Structural characterization of carbon nanofibers obtained by hydrocarbon pyrolysis," Carbon, vol. 39, no. 13, pp. 2003-2010, 2001.

[31] B. Lu, H. Huang, X. L. Dong, and J. P. Lei, "Catalytic pyrogenation synthesis of $\mathrm{C} / \mathrm{Ni}$ composite nanoparticles: controllable carbon structures and high permittivities," Journal of Physics D, vol. 43, no. 10, Article ID 105403, 6 pages, 2010.

[32] L. Liu, Y. Qin, Z.-X. Guo, and D. Zhu, "Reduction of solubilized multi-walled carbon nanotubes," Carbon, vol. 41, no. 2, pp. 331335, 2003.

[33] Y.-H. Li, C. Xu, B. Wei et al., "Self-organized ribbons of aligned carbon nanotubes," Chemistry of Materials, vol. 14, no. 2, pp. 483-485, 2002.

[34] L. Yan, P. R. Chang, and P. Zheng, "Preparation and characterization of starch-grafted multiwall carbon nanotube composites," Carbohydrate Polymers, vol. 84, no. 4, pp. 1378-1383, 2011.

[35] H. Naeimi, A. Mohajeri, L. Moradi, and A. M. Rashidi, "Efficient and facile one pot carboxylation of multiwalled carbon nanotubes by using oxidation with ozone under mild conditions," Applied Surface Science, vol. 256, no. 3, pp. 631-635, 2009.

[36] S. Y. Sawant, R. S. Somani, H. C. Bajaj, and S. S. Sharma, "A dechlorination pathway for synthesis of horn shaped carbon nanotubes and its adsorption properties for $\mathrm{CO}_{2}, \mathrm{CH}_{4}, \mathrm{CO}$ and $\mathrm{N}_{2}$," Journal of Hazardous Materials, vol. 227-228, pp. 317-326, 2012. 

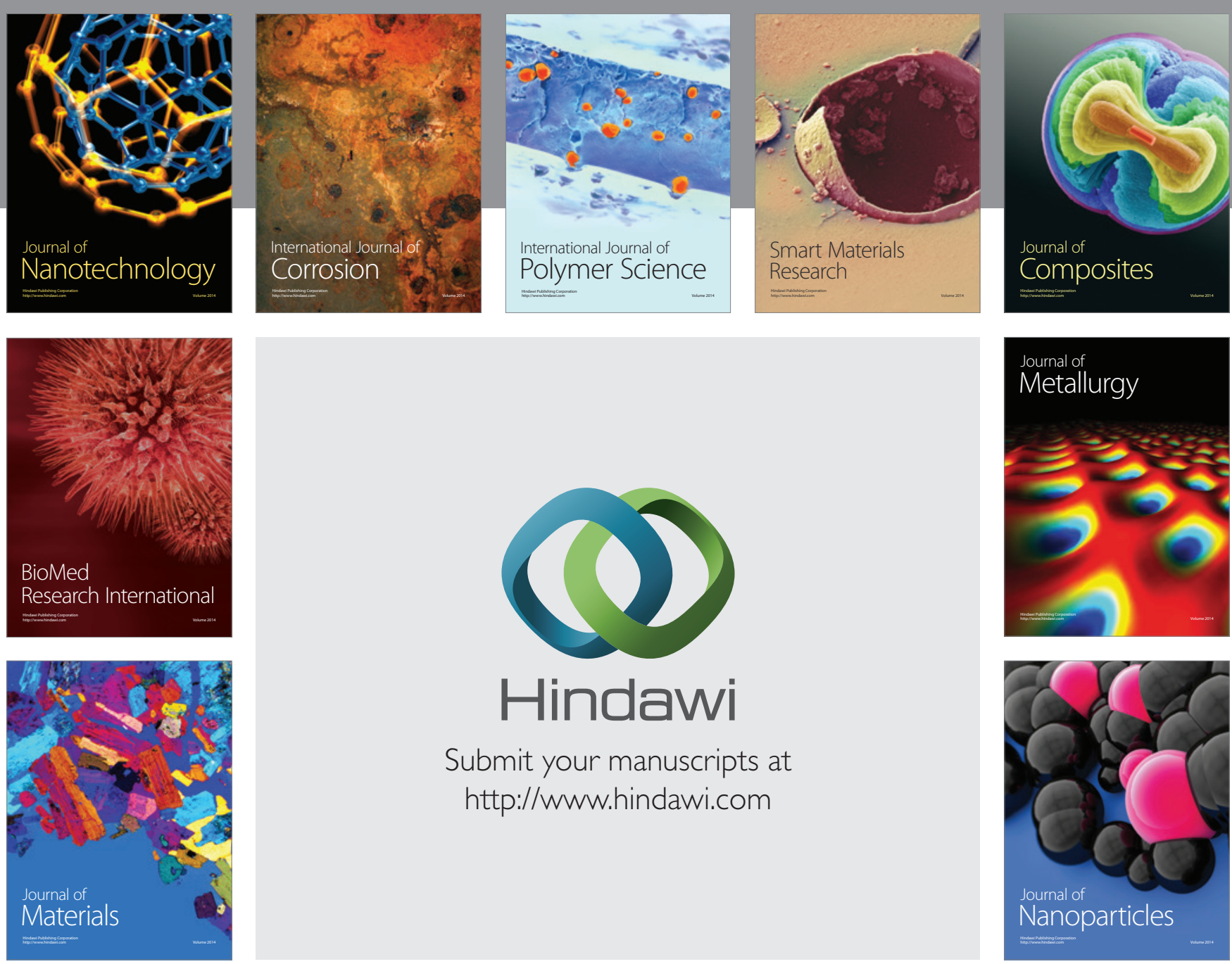

Submit your manuscripts at http://www.hindawi.com
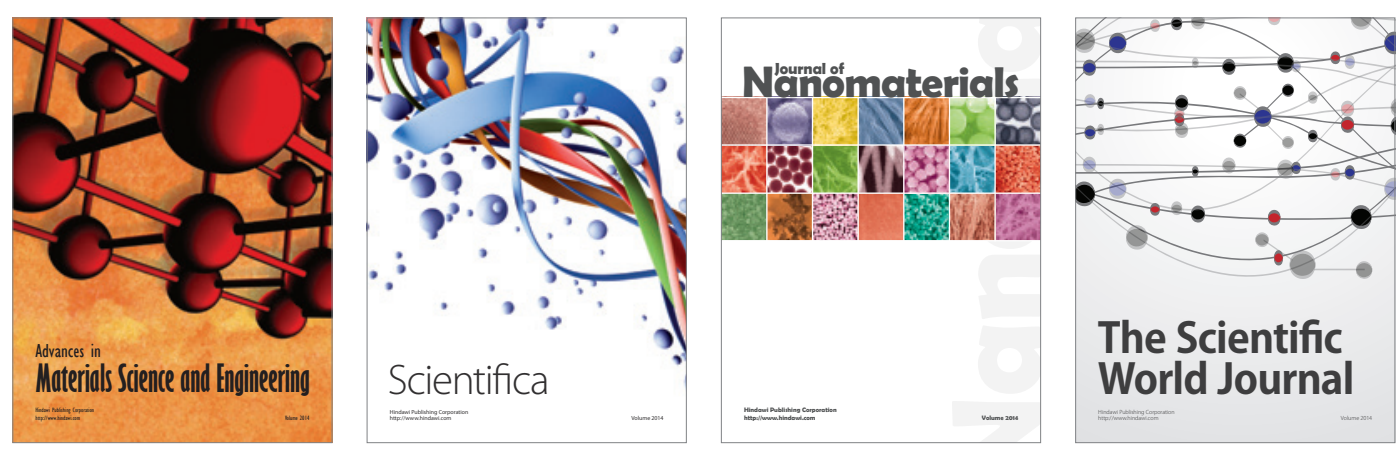

\section{The Scientific World Journal}
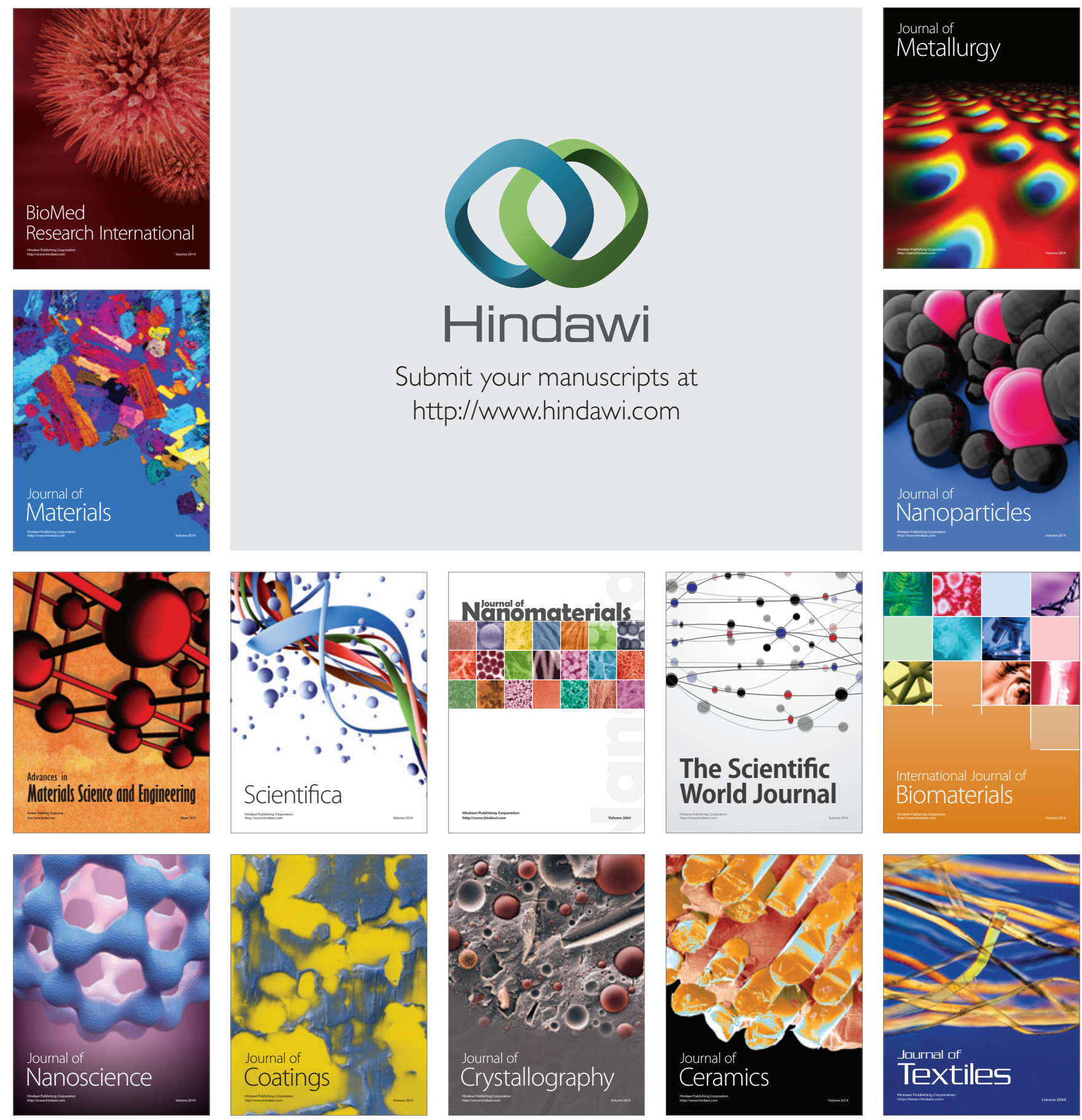